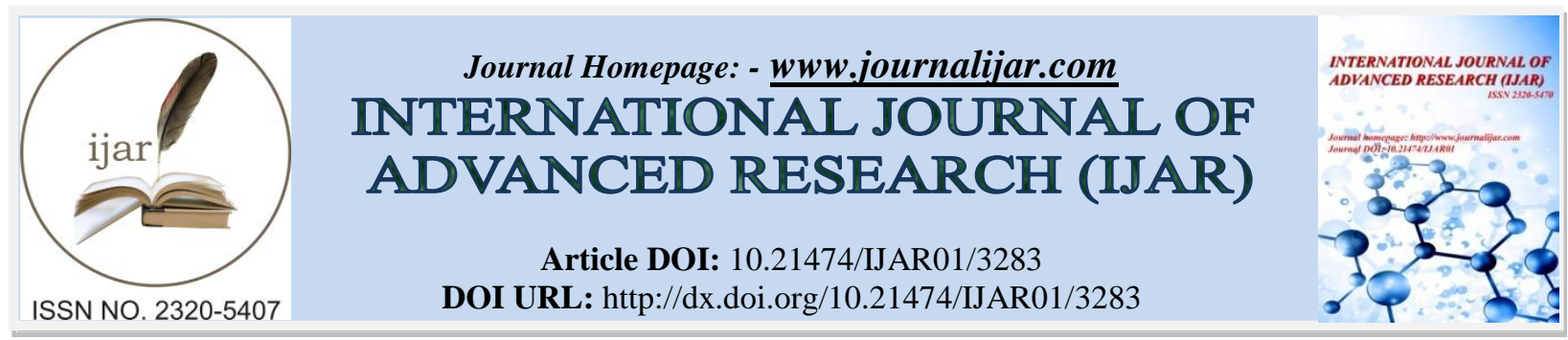

RESEARCH ARTICLE

\title{
RELATIONSHIP BETWEEN DIET AND ACNE AMONG RESIDENTS OF AL-MADINAH AL- MUNWARAH, SAUDI ARABIA.
}

Osama Mohammed Alsharif ${ }^{1}$, Samar Mohammed Albahlool ${ }^{2}$, Reham Mohammad Kharabah ${ }^{2}$, Arwa Talal Malosh $^{2}$, Abdulrahman Mohammed Albooq ${ }^{2}$, Ghada Badr Alharbi ${ }^{2}$, Akram Mohammad Bahader ${ }^{2}$, Nedal Ibrahim Bahader ${ }^{2}$, Zainab Abdulhadi Alabdulrahim ${ }^{2}$ and Salah Mohammed El Sayed ${ }^{3,4}$.

1. Department of Dermatology, King Fahd Hospital, Directorate of Health, Al-Madinah Al-Munawwarah, Saudi Arabia.

2. Internship Medical Education Programme, Taibah College of Medicine, Taibah University, Saudi Arabia.

3. Department of Clinical Biochemistry and Molecular Medicine, Taibah Faculty of Medicine, Taibah University, Al-Madinah Al-Munawwarah, Saudi Arabia.

4. Department of Medical Biochemistry, Sohag Faculty of Medicine, Sohag University, Egypt.

\section{Manuscript Info}

Manuscript History

Received: 12 December 2016

Final Accepted: 06 January 2017

Published: February 2017

\section{Abstract}

Background: Acne vulgaris is one of the most and common chronic inflammatory skin diseases, which affects people in both developing and developed countries. This study aimed to investigate and define the relation between diet and acne among residents of Al-Madinah AlMunawarah, Saudi Arabia.

Methodology: This cross-sectional study was conducted between October 2016 and January 2017 where all the participants were from Al-Madinah Al-Munwarah. Participation was done on a voluntary basis and all the participants filled an electronic questionnaire.

Results:- There was a significant association between acne and irregular menstruation $(\mathrm{p}=0.008)$, while no significant association was found between acne and other diseases. The belief in the ability of certain kinds of food (junk food, sweets, chocolate, soda, chips and spicy foods) to aggravate acne severity was significantly higher among participants with acne compared with participants with no acne $(\mathrm{p}<0.001, \quad \mathrm{p}<0.001, \quad \mathrm{p}<0.001, \mathrm{p}=0.01, \quad \mathrm{p}<0.001$ and $\mathrm{p}<0.001)$, respectively.

Conclusion:- The present findings suggest a positive association between some food and acne vulgaris in the Saudi context. An interventional dietary study will be required to further ascertain the effects of these foods on acne vulgaris.

Copy Right, IJAR, 2017,. All rights reserved.

\section{Introduction:-}

Acne vulgaris is one of the most and common chronic inflammatory skin diseases, which affects people in both developing and developed country, (1,2), it affects particularly teenagers between 15-17 years and about 15-20\% of young adults $(3,4)$. It can persist to adult life where several studies addressed that there is increased prevalence of adult having acne $(3,5)$. It is characterized by "sebum overproduction, follicular hyperkeratinization, and increased release of inflammatory-mediating chemicals along with androgens and other pathogenic influences". (1)

Corresponding Authors:-

Osama Mohammed Alsharif: Department of Dermatology, King Fahd Hospital, Directorate of Health, Al-Madinah Al-Munawwarah, Saudi Arabia.

Salah Mohammed El Sayed: Department of Clinical Biochemistry and Molecular Medicine, Taibah Faculty of Medicine, Taibah University, Al-Madinah Al-Munawwarah, Saudi Arabia. 
Several studies indicate that having acne can be a huge deterrent to adequate growth and self-confidence of young university students who represent the future of our country $(1,6)$ where physical appearance is one of the most sensitive aspects of our society and plays a vital role in our social and physiological well-being. It has a direct impact on our self-esteem and ability to function with confidence. One of the most intriguing facts of physical appearance is acne and it is a phenomenon which has affected all of us at some point in our lives (7-12). This aspect is of particular importance to teenagers and young adults who are constantly influenced by media to have a certain physical appearance in order to be accepted by their peers and society. (7-12)

Despite having such a pervasive impact, there are certain areas of this topic that are not given the attention they rightfully deserve. There have been extensive amount of research done on medication and other remedial actions to cure acne. There are numerous factors that contribute to the occurrence of acne in human body rather than a single cause. It is believed diet plays one of the more significant contributing factors directly and otherwise in acne existence. However, inadequacy in investigating the relationship between diet and acne is to say the least, alarming where the lack of attention given to this relationship is primarily due to the absence of a correlation between diet and acne found in earlier studies. However, more recent studies have shown a strong relation between diet and acne contrary to the common belief held in the past. (13)

Historically, the relationship between diet and acne has been highly debated, where in $19^{\text {th }}$ and first half of $20^{\text {th }}$ centuries, the relation between diet and acne was addressed strongly and all dermatologists recommended avoiding certain kinds of food (chocolate, fats, and sweets), then during the second half of $20^{\text {th }}$ century several studies were conducted and dismissed the relationship between diet and acne and considered it as a myth. However, during the last two decades, the relationship appeared on the surface again and a lot of studies were conducted that addressed the correlation between diet and acne. Those latest studies depended on several factors e.g. glycemic Index (GI) and glycemic load (GL). More understanding of acne pathogenesis, the role of endocrine mechanisms in acne pathogenesis and the necessary duration of time for a given treatment to influence acne development is needed $(6,14$ ,15).

Our study aimed to investigate and define the relation between diet and acne among residents of Al-Madinah AlMunawarrah, Saudi Arabia.

\section{Methodology:-}

This cross-sectional study was designed and conducted between October 2016 and January 2017, the participants were from Al-Madinah Al-Munwarah community, Saudi Arabia. Participants were between 16 to 40 years, and the participation was on a voluntary basis. An ethical approval was obtained from the ethical committee in the College of Medicine, Taibah University and all participants provided informed consent before filling the questionnaire. All eligible participants were asked to fill an electronic questionnaire, which consisted of two parts: the first part is demographic and anthropometric data (age, gender, weight, height, BMI, acne severity, acne medication, chronic illness and, history of oral contraceptive use), and the second part was regarding diet habits and food-aggravated acne beliefs. This questionnaire was presented to dermatologist for validation. The researchers divided the participants to four groups depending on acne severity (no acne, mild acne, moderate acne and severe acne).

All statistical analyses were performed using SPSS version20, categorical data was presented as numbers and percentages, and parametric data was presented as means and standard deviations (SDs). Chi square test was used to compare between acne severity groups regarding food habits and beliefs and to find the relation between acne severity and diet habits. $p$ values $<0.05$ were considered significant.

\section{Results:-}

Total of 580 adults (106 males, 474 females), half of them from the age group (21-30) joined the study. Two hundred ninety-one participants (50.2\%) reported no acne, $238(41.0 \%)$ reported mild acne, and $51(8.8 \%)$ reported moderate to severe acne. There were no differences in sex, BMI, and number of meals per day between groups. Participants with mild acne were significantly higher in groups age 16-25 (61.8\%) compared with participants with no acne or moderate to severe acne $(53.2 \%)(\mathrm{p}=0.001)$. Similarly, participants with mild acne were significantly higher $(72.6 \%)$ in receiving medication for treating their acne compared with participants with no acne or moderate to severe acne $(27.4 \%)(\mathrm{p}=0.001)$. There was a significant association between acne and irregular menstruation $(\mathrm{p}=0.008)$, while no significant association was found between acne and other diseases (Table 1). 
Participants with acne compared with participants with no acne reported a greater consumption of the following kinds of food per day: milk, rice, pasta, cheese, soda, sweet, coffee and tea with no significant difference, while there was significant difference in the consumption of the following food type: oil-butter, chips and white bread. Conversely, participants with no acne (compared with participants with acne) reported a greater consumption of the following kinds of food per day: fruits, vegetables, meat, egg, peas, yogurt and low fat milk with no significant difference, while there was a significant difference in the consumption of fish and nuts. On the other hand, the consumption of skimmed milk and brown bread were equal between both groups (Table 2).

A greater percentage of participants in the acne groups reported diet to influence acne severity (88.2\%) compared with participants with no acne $(11.8 \%)(\mathrm{p}<0.001)$. The results showed that the belief in the ability of some kinds of food (junk food, sweets, chocolate, soda, chips and spicy foods) to aggravate acne severity was significantly higher among participants with acne compared with participants with no acne ( $<<0.001, \mathrm{p}<0.001, \mathrm{p}<0.001, \mathrm{p}=0.01, \mathrm{p}<0.001$ and $\mathrm{p}<0.001$ ), respectively. Moreover, the belief in the ability of some kinds of food (fruits, vegetables, fish, brown bread and yogurt) to decrease acne severity was significantly higher among participants with acne compared with participants with no acne $(\mathrm{p}<0.001, \mathrm{p}<0.001, \mathrm{p}=0.002, \mathrm{p}=0.007$ and $\mathrm{p}<0.001)$, respectively (Table 3)

Table 1:- Demographic data and medical characteristics:

\begin{tabular}{|c|c|c|c|c|c|}
\hline characteristics & $\begin{array}{l}\text { Overall } \\
(\mathbf{n}=\mathbf{5 8 0})\end{array}$ & $\begin{array}{ll}\begin{array}{l}\text { No } \\
(\mathrm{n}=291)\end{array} & \text { acne } \\
\end{array}$ & $\begin{array}{ll}\begin{array}{l}\text { Mild } \\
(\mathrm{n}=238)\end{array} & \text { acne } \\
\end{array}$ & $\begin{array}{lll}\begin{array}{l}\text { Moderate } \\
(\mathrm{n}=51)\end{array} & \text { to } & \text { severe } \\
\end{array}$ & P value \\
\hline \multicolumn{6}{|l|}{$\mathbf{N}(\%)$} \\
\hline \multicolumn{6}{|l|}{ Age } \\
\hline less than 16 & $21(3.6 \%)$ & $\begin{array}{ll}7 & (2.4 \%) \\
\end{array}$ & $\begin{array}{ll}12 & (5.0 \%)\end{array}$ & $\begin{array}{ll}2 & (4.2 \%)\end{array}$ & \multirow[t]{7}{*}{ 0.0001* } \\
\hline $16-20$ & $88 \quad(15.2 \%)$ & $34 \quad(11.6 \%)$ & $48 \quad(20.2 \%)$ & $\begin{array}{ll}6 & (12.5 \%) \\
\end{array}$ & \\
\hline $21-25$ & $187(32.2 \%)$ & $82(27.9 \%)$ & $87 \quad(36.6 \%)$ & $18(37.5 \%)$ & \\
\hline $26-30$ & $109(18.8 \%)$ & $55 \quad(18.7 \%)$ & $47 \quad(19.7 \%)$ & $7 \quad(14.6 \%)$ & \\
\hline $31-35$ & $78 \quad(13.4 \%)$ & $47 \quad(16.0 \%)$ & $22(9.2 \%)$ & $\begin{array}{ll}9 & (18.8 \%) \\
\end{array}$ & \\
\hline $36-40$ & $\begin{array}{ll}60 & (10.3 \%) \\
\end{array}$ & $39 \quad(13.3 \%)$ & $16(6.7 \%)$ & $(10.4 \%)$ & \\
\hline more than 40 & $37 \quad(6.4 \%)$ & $30 \quad(10.2 \%)$ & $6 \quad(2.5 \%)$ & $(2.1 \%)$ & \\
\hline \multicolumn{6}{|l|}{ Gender } \\
\hline Male & $106(18.3 \%)$ & $\begin{array}{ll}61 \quad(20.7 \%) \\
\end{array}$ & $36 \quad(15.1 \%)$ & $\begin{array}{ll}9 & (18.7 \%) \\
\end{array}$ & \multirow[t]{2}{*}{0.2} \\
\hline Female & $474(81.7 \%)$ & $233(79.3 \%)$ & $202(84.9 \%)$ & $39(81.3 \%)$ & \\
\hline \multicolumn{6}{|l|}{ Meals } \\
\hline One meal & $11 \quad(1.9 \%)$ & $\begin{array}{ll}3 & (1.0 \%) \\
\end{array}$ & $\begin{array}{ll}6 & (2.5 \%) \\
\end{array}$ & $\begin{array}{ll}1 & (2.1 \%) \\
\end{array}$ & \multirow[t]{4}{*}{0.8} \\
\hline Two meals & $265(45.7 \%)$ & $129(44.3 \%)$ & $117(49.2 \%)$ & $\begin{array}{ll}9 & (39.6 \%) \\
\end{array}$ & \\
\hline Third meals & $238(41.0 \%)$ & $130(44.7 \%)$ & $\begin{array}{ll}86 & (36.1 \%)\end{array}$ & $20(41.7 \%)$ & \\
\hline More than 3 meals & $66 \quad(11.4 \%)$ & $29 \quad(10.0 \%)$ & $29 \quad(12.2 \%)$ & $\begin{array}{ll}8 & (16.7 \%) \\
\end{array}$ & \\
\hline \multicolumn{6}{|c|}{ Do you think there is a relation between diet and acne? } \\
\hline no & $82(14.3 \%)$ & $52(17.7 \%)$ & $25 \quad(10.5 \%)$ & $5 \quad(10.4 \%)$ & \multirow[t]{2}{*}{ 0.03* } \\
\hline yes & $497(85.7 \%)$ & $241(82.3 \%)$ & $213(89.5 \%)$ & $43 \quad(89.6 \%)$ & \\
\hline \multicolumn{6}{|c|}{ Receiving medication for treating acne } \\
\hline no & $379(65.7 \%)$ & $278(94.6 \%)$ & $92 \quad(38.7 \%)$ & $9 \quad(18.8 \%)$ & \multirow[t]{2}{*}{$0.0001 *$} \\
\hline yes & $201(34.7 \%)$ & $16(5.4 \%)$ & $146 \quad(61.3 \%)$ & $39 \quad(81.2 \%)$ & \\
\hline \multicolumn{6}{|c|}{ Contraceptive use $(n=474)$} \\
\hline No & $436(92.0 \%)$ & $217(90.8 \%)$ & $179(96.2 \%)$ & $40 \quad(93.8 \%)$ & \multirow[t]{2}{*}{$0.04 *$} \\
\hline yes & $38 \quad(8.0 \%)$ & $27 \quad(9.2 \%)$ & $8 \quad(3.8 \%)$ & $3 \quad(6.2 \%)$ & \\
\hline \multicolumn{6}{|l|}{ Chronic illness } \\
\hline No & $360(\%)$ & $186(51.7 \%)$ & $148(41.1 \%)$ & $26(7.2 \%)$ & 0.329 \\
\hline Hypertension & $26 \quad(\%)$ & $16(61.5 \%)$ & $8(30.8 \%)$ & $2(7.7 \%)$ & 0.352 \\
\hline Diabetes & $15 \quad(\%)$ & $9(60.0 \%)$ & $5(33.3 \%)$ & $1(6.7 \%)$ & 0.504 \\
\hline Obesity & $83 \quad(\%)$ & $44(53.0 \%)$ & $31(37.3 \%)$ & $8(9.6 \%)$ & 0.883 \\
\hline $\begin{array}{ll}\begin{array}{l}\text { Polycystic } \\
\text { syndrome }\end{array} & \text { ovarian } \\
\end{array}$ & $39 \quad(\%)$ & $17(43.6 \%)$ & $19(48.7 \%)$ & $3(7.7 \%)$ & 0.511 \\
\hline Thyroid disease & $18 \quad(\%)$ & $7(38.9 \%)$ & $8(44.4 \%)$ & $3(16.7 \%)$ & 0.174 \\
\hline Irregular ministration & $69 \quad(\%)$ & $25(36.3 \%)$ & $35(50.7 \%)$ & $9(13.0 \%)$ & $0.008^{*}$ \\
\hline \multicolumn{6}{|l|}{ Mean \pm SD } \\
\hline BMI & $25.3 \pm 6.3$ & $25.8 \pm 6.5$ & $24.7 \pm 6.1$ & $24.5 \pm 5.7$ & 0.2 \\
\hline
\end{tabular}


Table 2:- Association between food and acne severity

\begin{tabular}{|c|c|c|c|}
\hline \multirow{2}{*}{$\begin{array}{l}\text { Variables } \\
\text { (1 per day) }\end{array}$} & Acne severity & & \multirow[t]{2}{*}{ P value } \\
\hline & No acne & Acne & \\
\hline White bread & $58(49.6 \%)$ & $67(58.4 \%)$ & $0.03^{*}$ \\
\hline Brown bread & $44(50.0 \%)$ & $44(50 \%)$ & 0.3 \\
\hline Rice & $53(43.1 \%)$ & $70(56.9 \%)$ & 0.3 \\
\hline Pasta & $6(33.3 \%)$ & $12(66.7 \%)$ & 0.7 \\
\hline Fruits & $46(59.0 \%)$ & $32(41 \%)$ & 0.05 \\
\hline Vegetables & $55(48.7 \%)$ & $58(51.3 \%)$ & 0.1 \\
\hline Meat & $38(49.4 \%)$ & $39(50.7 \%)$ & 0.4 \\
\hline Fish & $4(57.1 \%)$ & $3(42.9 \%)$ & $0.02 *$ \\
\hline Egg & $24(60.0 \%)$ & $16(40.0 \%)$ & 0.1 \\
\hline Peas & $9(60.0 \%)$ & $6(40 \%)$ & 0.9 \\
\hline Nuts & $14(63.6)$ & $8(36.4 \%)$ & $0.009 *$ \\
\hline Yogurt & $53(57.0 \%)$ & $40(43 \%)$ & 0.3 \\
\hline Skimmed milk & $9(50.0 \%)$ & $9(50 \%)$ & 0.5 \\
\hline Low fat milk & $18(56.3 \%)$ & $14(44.8 \%)$ & 0.7 \\
\hline Milk & $24(46.2 \%)$ & $28(53.8 \%)$ & 0.2 \\
\hline Cheese & $50(47.2 \%)$ & $56(52.8 \%)$ & 0.1 \\
\hline Oil - butter & $10(38.5 \%)$ & $16(61.5 \%)$ & $0.0001^{*}$ \\
\hline Junk food & $7(38.9 \%)$ & $11(61.1 \%)$ & 0.06 \\
\hline Soda & $9(40.9 \%)$ & $13(59.1 \%)$ & 0.8 \\
\hline Sweet & $70(47.9 \%)$ & $76(52.1 \%)$ & 0.3 \\
\hline Coffee - tea & $57(49.1 \%)$ & $59(50.8 \%)$ & $0.04 *$ \\
\hline Chips & $11(29.7 \%)$ & $26(70.3 \%)$ & $0.01 *$ \\
\hline \multicolumn{4}{|l|}{ Water } \\
\hline 1 cup & $26(51 \%)$ & $25(49 \%)$ & \multirow[t]{5}{*}{0.03} \\
\hline $2-3$ cups & $92(43 \%)$ & $122(57 \%)$ & \\
\hline 4-6 cups & $123(55 \%)$ & $101(45 \%)$ & \\
\hline $7-8$ cups & $33(55.9 \%)$ & $26(44.1 \%)$ & \\
\hline More than 8 cups & $20(64.5 \%)$ & $11(35.5 \%)$ & \\
\hline
\end{tabular}

Table 3:- Beliefs on the ability of some kinds of food to aggravate or decrease acne severity

\begin{tabular}{|c|c|c|c|c|}
\hline \multirow{2}{*}{ Variables } & \multirow{2}{*}{\multicolumn{3}{|c|}{$\begin{array}{l}\text { Acne severity } \\
\text { none }\end{array}$}} & \multirow{2}{*}{$P$ value } \\
\hline & & & & \\
\hline \multicolumn{5}{|l|}{ Food aggravate acne } \\
\hline None & $2(11.8 \%)$ & $11(64.7 \%)$ & $4(23.5 \%)$ & $.000 *$ \\
\hline Lake of drinking water & $34(22.8 \%)$ & $98(65.8 \%)$ & $17(11.4 \%)$ & $.000 *$ \\
\hline Junk food & $34(22.5 \%)$ & $97(64.2 \%)$ & $20(13.2 \%)$ & $.000 *$ \\
\hline Sweets & $31(27.7 \%)$ & $69(61.6 \%)$ & $12(10.7 \%)$ & $.000 *$ \\
\hline Chocolate & $53(25.9 \%)$ & $129(62.9 \%)$ & $23(11.2 \%)$ & $.000 *$ \\
\hline Soda & $22(28.6 \%)$ & $48(62.3 \%)$ & $7(9.1 \%)$ & $.001 *$ \\
\hline Milk & $6(16.2 \%)$ & $26(70 . .3 \%)$ & $5(13.5 \%)$ & $.000 *$ \\
\hline White bread & $8(28.6 \%)$ & $17(60.7 \%)$ & $3(10.7 \%)$ & $.037 *$ \\
\hline Chips & $22(19.8 \%)$ & $74(66.7 \%)$ & $15(13.5 \%)$ & $.000 *$ \\
\hline Spicy food & $23(24.2 \%)$ & $60(63.2 \%)$ & $12(12.6 \%)$ & $.000 *$ \\
\hline Pizza & $8(24.2 \%)$ & $19(57.6 \%)$ & $6(18.2 \%)$ & $.001 *$ \\
\hline \multicolumn{5}{|l|}{ Food decrease acne } \\
\hline None & $16(17.6 \%)$ & $59(64.8 \%)$ & $16(17.6 \%)$ & $.000^{*}$ \\
\hline Fruits & $47(25.8 \%)$ & $117(64.3 \%)$ & $18(9.9 \%)$ & $.000 *$ \\
\hline Vegetables & $38(26.2 \%)$ & $94(64.8 \%)$ & $13(9.0 \%)$ & $.000 *$ \\
\hline Fish & $16(26.7 \%)$ & $39(65.0 \%)$ & $5(8.3 \%)$ & $.002 *$ \\
\hline Tuna & $10(28.6 \%)$ & $23(65.7 \%)$ & $2(5.7 \%)$ & .061 \\
\hline Brown bread & $12(26.7 \%)$ & $29(64.4 \%)$ & $4(8.9 \%)$ & $.007 *$ \\
\hline Low fat milk & $32(32.3 \%)$ & $59(59.6 \%)$ & $8(8.1 \%)$ & $.002 *$ \\
\hline Yogurt & $4(11.4 \%)$ & $24(68.6 \%)$ & $7(20.0 \%)$ & $.000^{*}$ \\
\hline
\end{tabular}




\section{Discussion:-}

The relationship between diet and acne was established since the 19th century, and a lot of studies were conducted to detect this relation and the types of food, which were considered as risk factors in developing acne. (16). The classic Saudi diet contains complex carbohydrates, vegetables, meat, and fish. However, in the last few decades, there was a significant increase in the rate of consumption of junk foods, sweets and sugary drinks particularly in the younger populations. In 2013, there was a study by Kumari et al. in which the authors reported the relation between growth hormone $(\mathrm{GH})$, insulin, and insulin-like growth factor-1 (IGF-1) hormones and the increase in sebum production during puberty $(16,17)$. Moreover, they reported that hyperinsulinenemia and insulin resistance were risk factors for acne development (16). Those conclusions and observations had been emphasized and recognized in subsequent studies (13, 18 and 19).In a study in New York in 2014, the authors reported the significant influence of diet with high GI and GL as a main cause that aggravated acne. Similar results were reported by the study of Colidan et al. where the authors reported the absence of acne among Papua New Guinea and Paraguay population due to their low glucose index diet $(5,20)$. Similar results were found in a big randomized control study $(20)$ where the authors reported the positive effect of low glucose load diet on decreasing acne lesion numbers, raising insulin sensitivity and decreasing weight $(19,21)$. The results of the current studies coincide with the previous study, where the results showed significant association between acne and consuming carbohydrate.

Several other studies demonstrated the link between acne and skimmed milk or whole milk but not with cheese (1618). This link is stronger with skimmed milk more than whole milk due to the fact that the link is not related to fatty substances in the milk but due to protein substance $(13,15)$, where several studies reported that milk has a three- to six-fold higher GL and insulin-trophic response than predicted. This means that the total consumption of milk proteins had a big influence on acne $(13,15)$. However the findings of the current study couldn't demonstrate this link. In contrast to Burris et al. study that was done among young adults in New York and addressed the relation between acne and milk, specially skimmed milk (17). Moreover, the study of Okoro in Nigeria reported higher acne prevalence among people who drink milk daily than those who don't (72.6\% vs. 62.0\%; p = 0.035). Also, they reported that acne has a relation with eating cake more than any other snacks such as biscuits. This may be supported by the fact that cakes need a large amount of milk in the content (18).

Our study found a significant association between acne and consumption of oil, butter and chips where similar results were found in two cross sectional studies conducted in 2010 in which the authors reported a link between acne development and increased consumption of fried foods (17, 22, and 23). In contrast, the authors in the Nigerian study didn't find this association (18).

Compared with the "no acne group", the consumption of fish was less among acne group. This coincided with the previous studies $(15,17,18)$. This negative effect on acne may be due to the fact that fish had a large amount of omega-3 fatty acids, which exhibit anti-inflammatory properties and help in decreasing IGF-1 levels. In 2012, a case-control study was conducted by Di Landro and colleagues where the authors determined the negative association between eating fish and acne severity (OR 0.68) and they concluded that frequent consumption of fish which is rich with n-3 fatty acids have a protective effect on acne $(15,24)$. However, few studies focused on this link but still there is a lack of evidence on this kind of association (17).

The current study didn't find any significant association between acne and yogurt, cheese, pasta, sweet and soda. However there was a significant association between drinking water and acne, where the group of "no acne" drink water more than the acne group. This is consistent with the belief that shortage in drinking water is a reason for aggravating acne. Regarding the beliefs of aggravation of acne by some kinds of food, most of the participants either from the "acne group" or the "no acne" group reported that soda, chips, pizza, sweets, spicy food and chocolate are related to an increase in acne. Similar results were found in New York study where the authors reported that there is no enough study about the relation between acne and chocolate. Further studies are recommended to detect this relation (17).

\section{Limitations:-}

The difference in the portion sizes of milk and fish consumed among groups is relatively small. Thus, the clinical relevance is questionable. Also, the nature of the study (cross-sectional) design may make the interpretations of the results limited where the results cannot be used to determine causation. 


\section{Conclusion:-}

The present findings suggest the presence of associations between some kinds of food and acne in the Saudi context, where the milk and saturated fat became on the top of risk factors. Fish consumption showed positive effects in reducing acne. Whenever the food is low in glucose load, low in saturated fat, and rich in grains, vegetables, fruits and Omega-3 fatty acids, the best effect on health and acne is achieved. An interventional dietary study will be required to further establish the effects of those foods on acne vulgaris.

\section{Acknowledgment:-}

The authors would like to acknowledge Dr. Osama Mohammed Alsharif, their supervisor, for his constant support, guidance and encouragement, and also Dr. Saja Hussein Majed Alsharif for her help in data collection.

\section{Disclosure statement:-}

The authors report no conflicts of interest. The authors alone are responsible for the content and writing of this article.

\section{References:-}

1. Bowe W, Patel NB, Logan AC .Acne vulgaris, probiotics and the gut-brain-skin axis: from anecdote to translational medicine. Benef Microbes. 2014 Jun 1;5(2):185-99.

2. White, Andrew, "The Effects of a Low Glycemic Load Diet on Acne Vulgaris in Adolescents and Young Adults" (2015). School of Physician Assistant Studies. Paper 533.

3. Norstedt S, Lindberg M. Dietary Regimes for Treatment of Acne Vulgaris: A Critical Review of Published Clinical Trials. ActaDermVenereol. 2016 Feb;96(2):283-4.

4. NorstedtSCan diet regimes be an option for treatment of acne vulgaris?A systematic review of the literature.Örebro University, School of Medicine, Degree project, 15 ECTS,JANUARY 2015

5. Bhate K, Williams HC. Epidemiology of acne vulgaris.Br J Dermatol. 2013 Mar;168(3):474-85.

6. Al Hussein Stela Mariana, Al Hussein Hussam, VariCamil Eugen3, Todoran Nicoleta1, Al Hussein Hamida2, Ciurba Adriana1, Dogaru Maria Titica . Diet, Smoking and Family History as Potential Risk Factors in Acne Vulgaris - a Community-Based Study. ActaMedicaMarisiensis 2016;62(2):173-181

7. Al Natour SH. Acne vulgaris: Perceptions and beliefs of Saudi adolescent males. J Fam Community Med 2017;24:34-43.

8. Bez Y, Yesilova Y, Ari M, Kaya MC, Alpak G, Bulut M. Predictive value of obsessive compulsive symptoms involving the skin on quality of life in patients with acne vulgaris. ActaDermVenereol 2013;93:679-83.

9. Timms RM. Moderate acne as a potential barrier to social relationships: Myth or reality? Psychol Health Med 2013;18:310-20.

10. Gupta MA, Gupta AK. Evaluation of cutaneous body image dissatisfaction in the dermatology patient.ClinDermatol 2013;31:72-9.

11. Magin P. Appearance-related bullying and skin disorders. ClinDermatol 2013;31:66-71.

12. Ritvo E, Del Rosso JQ, Stillman MA, La Riche C. Psychosocial judgements and perceptions of adolescents with acne vulgaris: A blinded, controlled comparison of adult and peer evaluations. Biopsychosoc Med 2011;5:11.

13. Danby FW. Nutrition and acne.ClinDermatol. 2010 Nov-Dec;28(6):598-604.

14. Bowe WP, Joshi SS and Shalita AR. Diet and acne. J AM ACAD DERMATOL .2009; 63(1)

15. Burris J, Rietkerk W, Woolf K. Acne: The Role of Medical Nutrition Therapy. J AcadNutr Diet. 2013 Mar;113(3):416-30.

16. WAN 16- Wan S. The cause and treatment of acne vulgaris: fact versus fiction. Master of Science 2015. Duke University

17. Burris J, Rietkerk W, Woolf K. Relationships of Self-Reported Dietary Factors and Perceived Acne Severity in a Cohort of New York Young Adults. J AcadNutr Diet. 2014 Mar;114(3):384-92.

18. Okoro EO, Ogunbiyi AO, George AO, Subulade MO. Association of diet with acne vulgaris among adolescents in Ibadan, southwest Nigeria.Int J Dermatol. 2016 Sep;55(9):982-8.

19. Ferdowsian HR, Levin S. Does diet really affect acne? Skin Therapy Lett. 2010 Mar;15(3):1-2, 5.

20. Cordain L, Lindeberg S, Hurtado M et al. Acne vulgaris: a disease of Western civilization. Arch Dermatol 2002; 138:1584-90.

21. Smith RN, Mann NJ, Braue A, et al. The effect of a high- protein, low glycemic-load diet versus a conventional, high glycemic-load diet on biochemical parameters associated with acne vulgaris: a randomized, investigatormasked, controlled trial. J Am AcadDermatol 57(2):247-56 (2007 Aug). 
22. Jung JY, Yoon MY, Min S, Hong JS, Choi YS, Suh DH.The influence of dietary patterns on acne vulgaris in Koreans.Eur J Dermatol. 2010;20(6):768-772.

23. Wei B, Pang Y, Zhu $\mathrm{H}$, et al. The epidemiology of adolescent acne in North East China. J EurAcadDermatolVenereol. 2010;24(8):953-957.

24. Di Landro A, Cazzaniga S, Parazzini F, et al. Family history, body mass index, selected dietary factors, menstrual history, and risk of moderate to severe acne in adolescents and young adults. J Am AcadDermatol. 2012;67(6):1129-1135. 